\title{
Evaluation of a rapid test for serological diagnosis of Chagas disease, in Mendoza, Argentina
}

\begin{abstract}
Chagas disease caused by Trypanosoma cruzi is a major public health problem. The diagnosis is difficult because there is no single test that has proven to be specific and sensitive enough for its detection. Diagnostic gold standard is the combination of two serological tests (of different format at the same time), and potentially a third test if the results are conflicting. These techniques often require special equipment. Immunochromatographic techniques are a practical and simple solution, recommended for field surveys. The purpose of this work was to evaluate the performance of a rapid diagnostic test for Trypanosoma cruzi on serum samples. The SD Bioline Chagas Ab Test ${ }^{\circledR}$ immunochromatographic test was evaluated analyzing 150 previously characterized serum samples. Inter-readers agreement, and assay specificity and sensitivity were analyzed. The specificity of the method was $99 \%$ and the sensitivity was $95 \%$. The results were acceptable to recommend this test for population studies. Further studies will be needed to analyze whether this test can be included, in combination with other test of different format, as and alternative serological pair for the gold standard.
\end{abstract}

Volume 9 Issue 2 - 2021

\author{
Martínez NI,' González Arra MC,' Delgado \\ D,' Sierra P,' Caccavari MV,', Ansola CP,3 \\ Vargas $\mathrm{SF}^{3}{ }^{\prime}$ Vera $\mathrm{ME},{ }^{3}$ Bontti $\mathrm{S}^{\prime}$ \\ 'Laboratorio de Referencia de Enfermedades Transmisibles, \\ Argentina \\ ${ }^{2}$ Laboratorio Hospital Luis Lagomaggiore, Mendoza,Argentina \\ ${ }^{3}$ Centro Regional de Hemoterapia, Mendoza, Argentina
}

Correspondence: Martínez NI, Laboratorio de Referencia de Enfermedades Transmisibles, Centro E. Coni, Godoy Cruz I87, Ciudad, Mendoza, Argentina,

Email laboratorioreferenciamza@yahoo.com.ar

Received: March 26, 2021 | Published: April 09, 2021

Keywords: chagas disease, immunochromatography, diagnostic test, sensitivity, specificity

\section{Introduction}

Chagas disease, caused by the parasite Trypanosoma cruzi, poses a public health problem in our country. ${ }^{1}$ Lack of appropriate diagnostic methods makes it a medical challenge. In this way, the serological diagnosis, according to current regulations in Argentina, ${ }^{2}$ must be performed by at least two tests based on different antigens in different formats, simultaneously, on the same serum sample. The most commonly used combination is Indirect HaemagglutinationEnzyme Immunoassay (HAI-EIA). If the result of these initial tests are conflicting (one test positive and the other negative), indirect immunofluorescence test (IIF) can be used. ${ }^{6}$ These tests are extensively used in the Laboratorio de Referencia de Enfermedades Transmisibles (LRET) (Reference Laboratory of Transmissible Diseases) - Centro Coni, located in Mendoza, Argentina) since it is the provincial reference laboratory on diagnosis of this infection. The mentioned methods require specialized equipment, not always available in small laboratories or when conducting studies in field condition. The lateral flow immunochromatographic (IC) technique, used in the rapid diagnostics test design for various infectious diseases, could provide a practical and simple solution to these diagnostic needs, and has been recommended by Pan American Health Organization (PAHO), as a single test, for field surveys. The aim of this study was to evaluate the performance of a rapid diagnostic test for infection by Trypanosoma cruzi, in pre-characterized samples.

\section{Materials and methods}

We evaluated the immunochromatographic test SD BIOLINE Chagas Ab Test $\AA$ (Standard Diagnostics) for the detection of antiTrypanosoma cruzi antibodies. We tested pre-characterized serum samples, by using standardized serological reactions: enzyme immunoassay (EIA) Chagatest ${ }^{\circledR}$ ELISA lysate (Wiener Laboratorios
S.A.I.C., Rosario, Argentina) and Indirect Hemagglutination (HAI) Chagatest ${ }^{\circledR}$ HAI (Wiener Laboratorios S.A.I.C., Rosario, Argentina). We analyzed a total of 150 serum samples stored at $-20^{\circ} \mathrm{C}: 90$ were provided by a blood bank (Centro Regional de Hemoterapia de Mendoza) and 60 were provided by a local hospital (Hospital Lagomaggiore). In the place of origin, all samples were anonymized and identified with numbers, while that in the LRET we analyzed the serum samples with the aforementioned HAI-EIA pair.

We recorded the results obtained in spreadsheets, which remained hidden, so as not to interfere with the interpretation of the rapid test. We processed the serum samples with the rapid test to be evaluated, following the manufacturer's instructions. We carried out the reading of the results 15 minutes after the start of the test, and the results were independently interpreted by three readers. We analyzed the agreement between readers using the kappa coefficient ${ }^{3}$ and we interpreted the results according to the scale by Landis and Koch. ${ }^{4}$ Finally we calculated the sensitivity and specificity values of the test under study.

\section{Results}

By using the HAI-EIA pair we obtained a total of 66 positive results, 74 negative and 10 discordant, therefore we excluded the latter from the analysis with the IC test. Two of the negative sera could not be processed by IC because they did not have enough volume. We carried out the rapid test in the 138 remaining pre-characterized serum samples ( 66 positive and 72 negative), we obtained 64 positive and 74 negative results by IC (Table 1). There was no mismatch of results between readers, so the kappa coefficient was equal to 1 ("near perfect" agreement according to the Landis and Koch classification) ${ }^{4}$ The specificity of the method was $99 \%$, while the sensitivity was $95 \%$ (Table 2). 
Table I Contingency table for SD BIOLINE immunochromatographic test Chagas Ab Test $₫$ (Standard Diagnostics) $(n=138)$

\begin{tabular}{llll}
\hline Results with IC SD* & Positive serum samples & Negative serum samples & Total \\
\hline IC SD Positive & 63 & $\mathrm{I}$ & 64 \\
IC SD Negative & 3 & 71 & 74 \\
Total & 66 & 72 & 138
\end{tabular}

Table 2 Diagnostic parameters obtained for the SD immunochromatographic test BIOLINE Chagas Ab Test $®$ (Standard Diagnostics)

\begin{tabular}{lll}
\hline Parameter & Percentage (\%) & Confidence interval 95\% \\
\hline Sensitivity & 95.45 & $87.29-99.05$ \\
Specificity & 98.61 & $92.50-99.9$ \\
\hline
\end{tabular}

*Abbreviations: IC, immunochromatography; SD, standard diagnostics; Ab, antibodies

\section{Conclusions}

Rapid diagnostic methods have great potential for application, due to their practicality and simplicity, and there have been designed for detection of various infectious diseases. Its enormous contribution has been demonstrated in the current SARS Cov-2 pandemic with the development of new rapid diagnostic tests for detection of both, antigens or antibodies against the virus. Its usefulness is even greater considering the recommendations on the use of IC, when available, in neglected diseases such as Chagas disease. ${ }^{6}$ The rapid method for diagnosis of Chagas disease evaluated in the present study generated sharp readings, which allowed obtain full agreement between readers. By the specificity values and sensitivity obtained, comparable to the rest of the methods available on the market, ${ }^{5}$ this IC is eligible for field surveys; even more taking into account the degree of "strong recommendation" made by PAHO, on the use of this test in this class of diagnoses. ${ }^{6}$ In this context, it is worth mentioning that this method is only validated for samples obtained by venipuncture (serum, plasma and whole blood), it would be extremely useful if the manufacturer carried out the validation on samples obtained by finger puncture, to be able to use it more conveniently in field conditions. This work was carried out using only serum samples, further studies would be needed, including whole blood samples, as well as samples with discordant results by other methods. If the performance of this test combined with another, were comparable to pairs of diagnostic tests used as gold standard, it could be considered to recommend this IC as an additional technique to be incorporated into serological diagnosis pairs.

\section{Acknowledgments}

We thank Laboratorios Bellandi y Barreras SRL and Abbott Laboratories Argentina S.A for providing the SD BIOLINE Chagas $\mathrm{Ab}$ Test ${ }^{\circledR}$ kits free of charge for this evaluation. We also thank the authorities of the participating institutions for making the necessary means available to carry out this work.

\section{Conflicts of interest}

The authors have declared that no competing interests exist.

\section{References}

1. Ministerio de Salud. Enfermedades infecciosas Chagas, atención del paciente con enfermedad de Chagas. Minist Salud Argentina; 2010.

2. Ministerio de Salud de la Nación. Guías para la atención al paciente infectado con Trypanosoma cruzi (Enfermedad de Chagas). Presidencia de la Nación Buenos Aires, Argentina; 2012.

3. Cerda JL, Villarroel Del LP. Evaluación de la concordancia interobservador en investigación pediátrica: Coeficiente de Kappa. Rev Chil Pediatr. 2008;79(1):54-58.

4. Landis JR, Koch GG. The measurement of observer agreement for categorical data. Biometrics. 1977;33(1):159-174.

5. Sánchez-Camargo CL, Albajar-Viñas P, Wilkins PP, et al. Comparative evaluation of 11 commercialized rapid diagnostic tests for detecting Trypanosoma cruzi antibodies in serum banks in areas of endemicity and nonendemicity. J Clin Microbiol. 2014;52(7):2506-2512.

6. PAHO. Guidelines for the Diagnosis and Treatment of Chagas Desease; 2019. 